\title{
The Effectiveness of Genetic Algorithm in Solving Simultaneous Equations
}

\author{
Ikotun Abiodun M. \\ Dept. of Computer Technology \\ Yaba College of Technology \\ PMB 2011 Yaba, Lagos-Nigeria
}

\author{
Lawal Olawale N. \\ Dept. of Computer Technology \\ Yaba College of Technology \\ PMB 2011 Yaba, Lagos-Nigeria
}

\author{
Adelokun Adebowale P. \\ Dept. of Computer Technology \\ Yaba College of Technology \\ PMB 2011 Yaba, Lagos-Nigeria
}

\begin{abstract}
There are several known conventional algorithms for solving system of linear equations, which are based on some theoretical principles. Finding solution to these set of equations through the evolutionary process of genetic algorithm is a new and developing research area of interest. The Genetic Algorithm approach follows the concept of solution evolution by stochastically developing generations of solutions population using a definite fitness function to determine the best fit solution to the problem. In this study, we experimented with a new non-conventional approach, based on biological evolution, to solving system of simultaneous linear equations. We discussed the origin of Genetic Algorithm and explore its applicability in solving system of simultaneous equations. We used Genetic Algorithm, on one hand, and Gaussian elimination method, on the other hand, to solve seven different systems of simultaneous linear equations. We then compared the results obtained from the two methods. It was observed that the Genetic Algorithm was very effective in discovering all possible sets of solutions that are applicable to any given system of simultaneous linear equations. Conventional numerical methods, such as Gaussian elimination method, produced a single set of solutions for a particular system of simultaneous linear equations, but GA was able to produce more than one set of solutions for certain systems of equations. For example, during our experiments with GA equation solver, one particular set of equations produced three different sets of perfect solutions, which perfectly fit into the equations.
\end{abstract}

\section{General Terms}

Genetic Algorithms

\section{Keywords}

Genetic Algorithm, Simultaneous equation, Gaussian elimination, Evolutionary computing, Artificial intelligence

\section{INTRODUCTION}

Genetic Algorithm is an Artificial Intelligence based methodology for solving problems. It is a non-mathematical, non-deterministic, but stochastic process or algorithm for solving optimization problems. The concept of Genetic Algorithm was introduced by John Holland in 1975 with the aim of making computers do what nature does. He was concerned with algorithms that manipulate strings of binary digits to find solution to problem in such a way that it exhibits the characteristics of natural evolution; that is, developing an algorithm that is an abstract of natural evolution. The idea of genetic algorithm by Holland stemmed from the evolutionary theory of Charles Darwin (1859) called Darwinian evolution. Darwinian evolutionary principle was based on the survival and reproduction of the fittest, stating that only the species that are fit to survive can reproduce their kind. The simulation of Charles Darwin's evolutionary process using the computer produces Genetic Algorithm (Holland J. H., 1975).

Systems of Linear Equations occur in various fields of Science, Social Sciences and Engineering to find solutions to some problems. There are several known conventional algorithms for solving system of linear equations, which are based on some theoretical principles. Finding solution to these set of equations through the evolutionary process of genetic algorithm is a new and developing research area of interest. The Genetic Algorithm approach follows the concept of solution evolution by stochastically developing generations of solutions population using a definite fitness function to determine the best fit solution to the problem. Genetic Algorithm has been applied to several scientific problems such as Scheduling, timetabling, travelling salesman's problem. It has been successfully exploited in many optimization problems but its application in solving systems of equations is still being researched into.

This study investigates the applicability and effectiveness of Genetic Algorithm to finding the solutions of systems of simultaneous linear equations, which involve a search for optimal values for the unknown variables in the equations that best fit the systems of linear equations. We compare the competence and efficiency of Genetic Algorithm with the numerical methods.

\section{LITERATURE REVIEW}

In 1950, Alan Turing wrote one of the earliest, and most significant, papers on machine intelligence titled "Computing machinery and intelligence". In the paper, Turing defined the intelligence behavior of a computer as the ability to achieve the human-level performance in cognitive tasks. Based on this idea, several research attempts were made to simulate complex thinking processes by inventing general methods for solving broad classes of problems. General-purpose search 
mechanisms were used to find solution to such problem. Apart from these classical and neo-classical methods, two prominent field of research arose, which is regarded as the connectionism (that is, neural network and parallel processing) and the evolutionary computing.

Evolutionary computation was inspired by the theory of evolution, which was proposed by Charles Darwin in 1859 . $\mathrm{He}$, in his book "The origin of Species" proposed that human and in fact all creatures are a product of evolution. In explaining biological evolution, Darwin opined that living creatures evolved through natural selection in which some species (that could favorably adapt to their natural environment by developing some characteristics over their several generations which made them strong enough) are preserved while those with less fitted characteristics are gradually phased out. He based his theory on some principal notions such as:

1. The struggle for existence - all living things are in contention over limited natural resources.

2. The survival of the fittest - nature selects the best fit for survival and propagation while the weak or less fit ones are eliminated (Wikipedia, 2010).

The survival of the reproduced offspring depends on its ability to 'fit' in and adapt to its environment notwithstanding the challenges posed by the environment as well as the contentions with other organisms in the same environment. Those that are 'well fitted' survive while the ones that cannot cope (otherwise 'less fitted') die off. This simple theory of biological evolution produced the platform for the various researches into the field of intelligence computing of evolutionary computation

\section{GENETIC ALGORITHM}

In designing Genetic Algorithm, the typical steps to be followed are:

Step1: Representation of the problem variable domain as a chromosome of a fixed length, the size of a chromosome population is chosen as well as the crossover probability.

Step 2: Definition of fitness function, which is used for measuring the quality of an individual chromosome in the problem domain. The fitness function establishes the basis for selecting chromosomes that will be mated during reproduction. Usually, the fitness function is defined over the genetic representation to measure the quality of the represented solution. Fitness functions are problem dependent and in cases where their definition is hard or even impossible, then interactive genetic Algorithm is used.

Step 3: Random generation of an initial population of chromosomes of a fixed size.

Step 4: Calculation of fitness function for each individual chromosome.

Step 5: Selection of pairs of chromosomes for mating from the current population. Parent chromosomes are selected with a probability related to their fitness. The highly fit chromosomes have a higher probability of being selected for mating.

Step 6: Application of the genetic operations (crossover and mutation) for creating pairs of offspring chromosomes.

Step 7: Placement of the created offspring chromosomes in the new population

Step 8: Repetition of step 5 through step 7 until the size of the new chromosome population becomes equal to the size of the initial population.

Step 9: Replacement of the initial (previous) parent chromosome population with the new offspring population.

Step 10: Repeat Step 4 through Step 9 until the termination criterion is satisfied.

(Wikipedia, 2010; Zbigniew Michalewicz, 1996; Fogel David B., 1998; Franz Rothlauf, 2006; Goldberg, D. E., 1989; Goldberg David E., 1989)

The termination criterion could be any of the following:

1. Attaining a known optimal or acceptable solution level or

2. A maximum number of generations has been reached.

\section{APPLICATION OF GENETIC ALGORITHM TO SYSTEM OF LINEAR EQUATIONS}

Systems of equations are functions of at least two variables. It can either be linear or non-linear, and to obtain a solution, the system should be non-singular and have a point in space where it coincides.

A system of linear equations has the form:

$$
\begin{gathered}
a_{11} x_{1}+a_{12} x_{2}+\ldots a_{1 N} x_{N}=y_{1} \\
a_{21} x_{1}+a_{22} x_{2}+\ldots a_{2 N} x_{N}=y_{1} \\
\cdot \\
\cdot \\
\cdot \\
a_{N 1} x_{1}+a_{N 2} x_{2}+\ldots a_{N N} x_{N}=y_{N}
\end{gathered}
$$

which is represented in matrix-vector form as:

$$
\mathrm{Ax}=\mathrm{y}
$$

where $\mathrm{x}$ are unknown variables, $\mathrm{N}$ is the number of unknown variables, and a are constants, represented by the coefficient matrix A (Strang Gilbert, 2007).

The important information needed in genetic algorithm include objective function, and the representation scheme in a form of a coded string, containing information about the possible solutions. Evaluation of a possible solution is done after every set of genetic operations (Simon Mardle and Sean Pascoe, 1999).

Therefore, the simultaneous systems of equations can be solve using genetic algorithm if we can express it in form of an objective function, and a solution is said to be correct if it can satisfy all of the equations involving those variables. That is:

$$
\begin{aligned}
& F 1\left(x_{1}, x_{2}, x_{3}, \ldots, x_{n}\right)-a_{1}=0 \\
& F 2\left(x_{1}, x_{2}, x_{3}, \ldots, x_{n}\right)-a_{2}=0 \\
& \ldots . \\
& F n\left(x_{1}, x_{2}, x_{3}, \ldots, x_{n}\right)-a_{n}=0
\end{aligned}
$$

or approximately, the 
absolute value of $\left(F 1\left(x_{1}, x_{2}, x_{3}, \ldots, x_{n}\right)-a_{1}\right)$, AND absolute value of $\left(F 2\left(x_{1}, x_{2}, x_{3}, \ldots, x_{n}\right)-a_{2}\right)$, AND $\cdots$

absolute value of $\left(F n\left(x_{1}, x_{2}, x_{3}, \ldots, x_{n}\right)-a_{n}\right)$

must be all at minimum.

The last set of equations is actually the objective function that is needed by Genetic Algorithm (Simon Mardle and Sean Pascoe, 1999)

\section{METHODOLOGY}

To demonstrate the applicability of genetic algorithm in finding the solution to the system of equation, the genetic algorithm paradigm has been applied to find the values for the unknowns in the equations. This study utilizes randomly generated data to represent each unknown variables in a system of simultaneous linear equations, which constitutes each chromosome. Several of the chromosomes initially generated form the initial generation. In finding the chromosome fitness, the randomly generated vector of values (genes) for all the unknowns were used to evaluate each line of the equation. The results obtained were subtracted from the right hand side (RHS) values of the original equation. The differences obtained were summed and the summation squared, that is, (sum of difference) $)^{2}$.

The right hand side values of each original equation were also summed and the summation also squared, that is, (sum of RHS) ${ }^{2}$. To compute the fitness of each chromosome, the concept of coefficient of multiple determination $\left(R^{2}\right)$ was used. This concept is also called the squared multiple correlation coefficient which is obtained by:

$\mathrm{R}^{2}=\left((\text { sum of RHS })^{2}-(\text { sum of difference })^{2}\right) /(\text { sum of RHS })^{2}$

The values of $R^{2}$ range between 0.0 and 1.0 (i.e. $0.0 \leq R^{2} \leq$ 1.0 ); and the fitness values that are closer to 1 imply a better fitness while a fitness value of 1.0 gives the best fitness that produces the most accurate solution to the equations.

A well fitted set of generation forms the initial population for the next generation and subsequently until the stopping criterion of fitness of 1.0 or very close to 1 is obtained or the maximum generation indicated in the program has been reached.

The computer program developed in this study follows the general standard procedure for genetic algorithms. We used Visual Basic 6.0 for the program development.

\subsection{Representation}

In generating initial values for each unknown in the equation which makes up a vector of values (chromosome) for the first generation, integer values were randomly generated for each variable. The values were then used in each line of equation to find the fitness of each chromosome. Integer value encoding is applied and the integer values were directly manipulated. During the crossover operation and mutation operation, the genes (integer values) in each chromosome selected for the respective operation were used.

\section{EXPERIMENTS}

The genetic algorithm simultaneous linear equation solver program was run several times using seven different sets of simultaneous linear equations to investigate the applicability of genetic algorithm in solving systems of linear equations. The population sizes as well as the number of generations were varied during the experimentation in order to observe their effects on the solution generation.

\section{RESULTS}

To investigate the applicability of genetic algorithm to solving system of linear equations, several systems of linear equations (positive integer only) of different sizes such as $3 \times 3,4 \times 4$ were used and the results obtained reported in table 1 below:

Table 1: Results from genetic algorithm and Gaussian Elimination methods of solving systems of linear equations

\begin{tabular}{|c|l|l|l|l|}
\hline $\begin{array}{c}\text { Experiment } \\
\text { No. }\end{array}$ & \multicolumn{1}{|c|}{ Equations } & \multicolumn{1}{c|}{$\begin{array}{c}\text { GA } \\
\text { Results }\end{array}$} & $\begin{array}{c}\text { Gaussian } \\
\text { Elimination } \\
\text { Results }\end{array}$ & $\begin{array}{c}\text { Actual } \\
\text { Solutions }\end{array}$ \\
\hline 1. & $\mathrm{x}_{1}+2 \mathrm{x}_{2}+3 \mathrm{x}_{3}=14$ & $\mathrm{x}_{1}=1$ & $\mathrm{x}_{1}=0$ & $\mathrm{x}_{1}=1$ \\
& $\mathrm{x}_{1}+\mathrm{x}_{2}+\mathrm{x}_{3}=6$ & $\mathrm{x}_{2}=2$ & $\mathrm{x}_{2}=4$ & $\mathrm{x}_{2}=2$ \\
& $3 \mathrm{x}_{1}+2 \mathrm{x}_{2}+\mathrm{x}_{3}=10$ & $\mathrm{x}_{3}=3$ & $\mathrm{x}_{3}=2$ & $\mathrm{x}_{3}=3$ \\
& & $\mathrm{x}_{1}=0$ & & \\
& & $\mathrm{x}_{2}=4$ & & \\
& & $\mathrm{x}_{3}=2$ & & \\
& & $\mathrm{x}_{1}=2$ & & \\
& & $\mathrm{x}_{2}=0$ & & \\
\hline 2. & $2 \mathrm{x}_{1}+4 \mathrm{x}_{2}+\mathrm{x}_{3}=5$ & $\mathrm{x}_{3}=4$ & & \\
& $4 \mathrm{x}_{1}+4 \mathrm{x}_{2}+3 \mathrm{x}_{3}=8$ & $\mathrm{x}_{2}=1$ & $\mathrm{x}_{2}=-0.5$ & $\mathrm{x}_{1}=0$ \\
& $4 \mathrm{x}_{1}+8 \mathrm{x}_{2}+\mathrm{x}_{3}=9$ & $\mathrm{x}_{3}=1$ & $\mathrm{x}_{3}=1$ & $\mathrm{x}_{2}=1$ \\
& & & & \\
\hline
\end{tabular}




\begin{tabular}{|c|c|l|l|l|}
\hline $\begin{array}{c}\text { Experiment } \\
\text { No. }\end{array}$ & \multicolumn{1}{|c|}{ Equations } & \multicolumn{1}{|c|}{ GA } \\
Results & $\begin{array}{c}\text { Gaussian } \\
\text { Elimination } \\
\text { Results }\end{array}$ & $\begin{array}{c}\text { Actual } \\
\text { Solutions }\end{array}$ \\
\hline 3. & $10 \mathrm{x}_{1}+\mathrm{x}_{2}+\mathrm{x}_{3}=12$ & $\mathrm{x}_{1}=1$ & $\mathrm{x}_{1}=1$ & $\mathrm{x}_{1}=1$ \\
& $2 \mathrm{x}_{1}+10 \mathrm{x}_{2}+\mathrm{x}_{3}=13$ & $\mathrm{x}_{2}=1$ & $\mathrm{x}_{2}=1$ & $\mathrm{x}_{2}=1$ \\
& $2 \mathrm{x}_{1}+2 \mathrm{x}_{2}+10 \mathrm{x}_{3}=14$ & $\mathrm{x}_{3}=1$ & $\mathrm{x}_{3}=1$ & $\mathrm{x}_{3}=1$ \\
\hline 4. & $\mathrm{x}_{1}+2 \mathrm{x}_{2}+3 \mathrm{x}_{3}=6$ & $\mathrm{x}_{1}=1$ & $\mathrm{x}_{1}=1$ & $\mathrm{x} 1=1$ \\
& $2 \mathrm{x}_{1}+4 \mathrm{x}_{2}+\mathrm{x}_{3}=7$ & $\mathrm{x}_{2}=1$ & $\mathrm{x}_{2}=1$ & $\mathrm{x} 2=1$ \\
& $3 \mathrm{x}_{1}+2 \mathrm{x}_{2}+9 \mathrm{x}_{3}=14$ & $\mathrm{x}_{3}=1$ & $\mathrm{x}_{3}=1$ & $\mathrm{x} 3=1$ \\
\hline 5. & $2 \mathrm{x}_{1}+\mathrm{x}_{2}+3 \mathrm{x}_{3}=13$ & $\mathrm{x}_{1}=1$ & $\mathrm{x}_{1}=0.9999$ & $\mathrm{x}_{1}=1$ \\
& $\mathrm{x}_{1}+5 \mathrm{x}_{2}+\mathrm{x}_{3}=14$ & $\mathrm{x}_{2}=2$ & $\mathrm{x}_{2}=2$ & $\mathrm{x}_{2}=2$ \\
& $3 \mathrm{x}_{1}+\mathrm{x}_{2}+4 \mathrm{x}_{3}=17$ & $\mathrm{x}_{3}=3$ & $\mathrm{x}_{3}=3.0001$ & $\mathrm{x}_{3}=3$ \\
\hline 6. & $2 \mathrm{x}_{1}+4 \mathrm{x}_{2}+8 \mathrm{x}_{3}=44$ & $\mathrm{x}_{1}=4$ & $\mathrm{x}_{1}=4$ & $\mathrm{x}_{1}=4$ \\
& $4 \mathrm{x}_{1}+6 \mathrm{x}_{2}+10 \mathrm{x}_{3}=66$ & $\mathrm{x}_{2}=5$ & $\mathrm{x}_{2}=5$ & $\mathrm{x}_{2}=5$ \\
& $6 \mathrm{x}_{1}+8 \mathrm{x}_{2}+10 \mathrm{x}_{3}=84$ & $\mathrm{x}_{3}=2$ & $\mathrm{x}_{3}=2$ & $\mathrm{x}_{3}=2$ \\
& & & & \\
\hline 7. & $4 \mathrm{x}_{1}+3 \mathrm{x}_{2}+2 \mathrm{x}_{3}+\mathrm{x}_{4}=10$ & $\mathrm{x}_{1}=1$ & $\mathrm{x}_{1}=0.7355$ & $\mathrm{x}_{1}=1$ \\
& $3 \mathrm{x}_{1}+2 \mathrm{x}_{2}+\mathrm{x}_{3}+4 \mathrm{x}_{4}=9$ & $\mathrm{x}_{2}=0$ & $\mathrm{x}_{2}=0.12011$ & $\mathrm{x}_{2}=0$ \\
& $2 \mathrm{x}_{1}+\mathrm{x}_{2}+4 \mathrm{x}_{3}+3 \mathrm{x}_{4}=14$ & $\mathrm{x}_{3}=3$ & $\mathrm{x}_{3}=2.1114$ & $\mathrm{x}_{3}=3$ \\
& $\mathrm{x}_{1}+4 \mathrm{x}_{2}+3 \mathrm{x}_{3}+2 \mathrm{x}_{4}=10$ & $\mathrm{x}_{4}=0$ & $\mathrm{x}_{4}=2.475$ & $\mathrm{x}_{4}=0$ \\
\hline
\end{tabular}

\section{DISCUSSION OF RESULTS}

In the course of this research work, the genetic algorithm has been successfully applied in finding solutions of systems of linear equations. During the experimentation, it was observed that the Genetic Algorithm (GA) equation solver was able to find all possible sets of solutions that are applicable to any given set of simultaneous linear equations.

From table 1 above, the following can be observed:

1. From experiment 1, the GA solution was able to detect other possible solutions apart from the actual result obtained from the Gaussian elimination method. This is a great feat from GA.

2. From experiment 2 and 7, the GA solution produced the same solution set as the actual solution, while Gaussian elimination method failed produced a wrong solution set.

3. From experiment 5, the Gaussian elimination method produced a result that is only close to the actual solution while the GA produced the actual solution.

From the observations stated above, we can make the following inferences:

1. Genetic Algorithm (GA) paradigm has been successfully applied in solving the systems of linear equations of positive integer.

2. GA was able to discover other solutions whose fitness was very close to 1 , producing very close substitute (or exact) to actual solutions.

\section{CONCLUSION}

It was observed that the GA equation solver was able to find all possible sets of solutions that are applicable to any given system of simultaneous linear equations. Conventional numerical methods always produce a set of solutions for a particular system of simultaneous linear equations, but GA was able to produce more than one set of solutions for certain systems of equations. For example, during our experiments with GA equation solver, one particular set of equations produced three different set of perfect solutions, which perfectly fit into the equations. By this we can conclude that GA is more effective than conventional numerical methods of solving system of simultaneous equations.

\section{REFERENCES}

[1] Holland J. H. 1975. Adaptation in Natural and Artificial Systems, University of Michigan Press, USA.

[2] Wikipedia 2010. System of Linear Equation.

[3] Zbigniew Michalewicz 1996. Genetic Algorithms + Data Structures = Evolution Program, Third, Revised and Expanded Edition, Springer, USA.

[4] Fogel David B. 1998. Evolutionary Computation: The Fossil Record, IEEE Press, New York.

[5] Franz Rothlauf 2006. Representations for Genetic and Evolutionary Algorithms, Second Edition, Springer, USA.

[6] Goldberg, D. E. 1989. Genetic Algorithms in Search, Optimization, and Machine Learning, Addison-Wesley, USA.

[7] Strang Gilbert 2007. Linear Algebra and Its Applications. Pacific Grove: Brooks Cole.

[8] Simon Mardle and Sean Pascoe 1999. An overview of genetic algorithms for the solution of optimization problems, Volume 13, Issue 1, http://www.economicsnetwork.ac.uk/cheer.htm 